NASA/TM-1998-208489

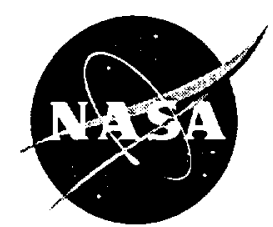

\title{
Performance of Surface-Mount Ceramic and Solid Tantalum Capacitors for Cryogenic Applications
}

Ahmad Hammoud and Scott Gerber

Dynacs Engineering Corp., Cleveland, Ohio 44135

Richard L. Patterson

Lewis Research Center, Cleveland, Ohio

Thomas L. MacDonald

Northrop Grumman-ESSD, Baltimore, Maryland

Prepared for the

Electrical Insulation and Dielectric Phenomena

sponsored by the Institute of Electrical and Electronics Engineers

Atlanta, Georgia, October 25-28, 1998

National Aeronautics and

Space Administration

Lewis Research Center 
Since its founding, NASA has been dedicated to the advancement of aeronautics and space science. The NASA Scientific and Technical Information (STI) Program Office plays a key part in helping NASA maintain this important role.

The NASA STI Program Office is operated by Langley Research Center, the Lead Center for NASA's scientific and technical information. The NASA STI Program Office provides access to the NASA STI Database, the largest collection of aeronautical and space science STI in the world. The Program Office is also NASA's institutional mechanism for disseminating the results of its research and development activities. These results are published by NASA in the NASA STI Report Series, which includes the following report types:

- TECHNICAL PUBLICATION. Reports of completed research or a major significant phase of research that present the results of NASA programs and include extensive data or theoretical analysis. Includes compilations of significant scientific and technical data and information deemed to be of continuing reference value. NASA's counterpart of peerreviewed formal professional papers but has less stringent limitations on manuscript length and extent of graphic presentations.

- TECHNICAL MEMORANDUM. Scientific and technical findings that are preliminary or of specialized interest, e.g., quick release reports, working papers, and bibliographies that contain minimal annotation. Does not contain extensive analysis.

- CONTRACTOR REPORT. Scientific and technical findings by NASA-sponsored contractors and grantees.
- CONFERENCE PUBLICATION. Collected papers from scientific and technical conferences, symposia, seminars, or other meetings sponsored or cosponsored by NASA.

- SPECIAL PUBLICATION. Scientific, technical, or historical information from NASA programs, projects, and missions, often concerned with subjects having substantial public interest.

- TECHNICAL TRANSLATION. Englishlanguage translations of foreign scientific and technical material pertinent to NASA's mission.

Specialized services that complement the STI Program Office's diverse offerings include creating custom thesauri, building customized data bases, organizing and publishing research results ... even providing videos.

For more information about the NASA STI Prcigram Office, see the following:

- Access the NASA STI Program Home Page at http://wwow.sti.nasa.gov

- E-mail your question via the Internet to help@sti.nasa.gov

- Fax your question to the NASA Access Help Desk at (301) 621-0134

- Telephone the NASA Access Help Desk at (301) 621-0390

- Write to: NASA Access Help Desk NASA Center for AeroSpace Information 7121 Standard Drive Hanover, MD 21076 


\section{Performance of Surface-Mount Ceramic and Solid Tantalum Capacitors for Cryogenic Applications}

\author{
Ahmad Hammoud \& Scott Gerber \\ Dynacs Engineering Corp. \\ NASA Lewis Research Center \\ Cleveland, Ohio 44135
}

\author{
Richard L. Patterson \\ NASA Lewis Research Center \\ 21000 Brookpark Road \\ Cleveland, Ohio 44135
}

\author{
Thomas L. MacDonald \\ Northrop Grumman - ESSD \\ P.O. Box 1521, MS 3103 \\ Baltimore, Maryland 21203
}

\begin{abstract}
Low temperature electronics are of great interest for space exploration programs. These include missions to the outer planets, earth-orbiting and deep-space probes, remote-sensing and communication satellites. Terrestrial applications would also benefit from the availability of low temperature electronics. Power components capable of low temperature operation would, thus, enhance the technologies needed for the development of advanced power systems suitable for use in harsh environments. In this work, ceramic and solid tantalum capacitors were evaluated in terms of their dielectric properties as a function of temperature and at various frequencies. The surface-mount devices were characterized in terms of their capacitance stability and dissipation factor in the frequency range of $50 \mathrm{~Hz}$ to $100 \mathrm{kHz}$ at temperatures ranging from room temperature $\left(20^{\circ} \mathrm{C}\right)$ to about liquid nitrogen temperature $\left(-190^{\circ} \mathrm{C}\right)$. The results are discussed and conclusions made concerning the suitability of the capacitors investigated for low temperature applications.
\end{abstract}

\section{Introduction}

Advanced electrical systems and electronic circuits emphasize compactness, lightweight, increased energy density, reliability and highly efficient operation. In addition, exposure and operation of these power systems in hostile environments, where extreme temperatures are encountered, is anticipated in many applications. For example, in NASA future missions, which include planetary exploration, space probes, and communication satellites, high power electrical components and systems must operate reliably and efficiently in very cold environments. Electronic instrumentation and power systems deployed near planet Pluto, for instance, will be exposed to temperatures as low as $-229^{\circ} \mathrm{C}$ [1]. Commercial remote-sensing satellites, and those used for military applications, typically employ electro-optical sensors and associated readout circuitry that must operate at cryogenic temperature levels approaching $-200^{\circ} \mathrm{C}$ in order to mitigate the effects of dark current and thermal background radiation.

Low temperature encounters will also exist in many terrestrial applications. These include superconducting energy storage media, magnetic levitation transportation systems, cryogenic medical research and instrumentation, as well as arctic and antarctic exploratory missions. The development of electrical components and systems capable of extreme temperature operation represents, therefore, a key element to meeting the technological challenges and to fulfilling the requirements of advanced space and terrestrial power systems. For space-based power subsystems, power electronics capable of low temperature operation will not only survive the harsh environments, but will reduce system size and weight by eliminating the need for radioactive heating units and associated equipment needed to keep the on-board electronics warm in order to maintain operation [2]. The benefits of reducing a system's size and weight will have a great impact on improving reliability and increasing lifetime [3], increasing energy densities, increasing payload capability, and reducing launch costs.

For space-based imaging systems, such as the Space Based Infra-Red System (SBIRS) currently under development by Northrop Grumman, cryogenic detector arrays, and analog/digital processor units must be interconnected in such a way that heat transfer to the $\mathbb{R}$ detectors is minimized. In order to minimize the thermal parasitic load on the passive cooler for the arrays, cable interconnects having low thermal conductivity (and relatively high DC resistance) must be used between the cold detectors and the warm analog/digital processor units. However, in order to meet the dynamic load demands of the detector's digital command interface and cable driver stages at the cold end of the interconnect, local reservoir or bypass capacitors, capable of retaining adequate charge storage ability and low loss tangents at cryogenic temperatures, are essential. Alternative coling schemes and more conventional cabling would relax this requirement. Thus, the successful use of these capacitors at cryogenic temperatures will permit system-level trades, such as those involving heat leakage and detector thermal performance, to be made with less impact on the performance of constituent electronic subassemblies.

Research and development efforts are underway at the NASA Lewis Research Center to develop lightweight, reliable wide temperature power systems for space missions and aerospace applications [4]. Development efforts are underway at Northrop Grumman on infra-red imaging platforms, where the use of passive cryogenic components would greatly enhance system-level design flexibility [5]. During the course of this work, ceramic and solid tantalum capacitors were evaluated in terms of 
their dielectric properties as a function of temperature and at various frequencies. The results obtained are presented and discussed in this paper.

\section{Experimental Procedures}

Five different capacitors with different ratings, selected by Northrop Grumman Corporation, were investigated in this work. These surface-mount devices included two ceramic multi-layer chip capacitors manufactured by Presidio Components, and three solid tantalum chip capacitors manufactured by Sprague Division of Vishay Intertechnology. Five samples of each capacitor were provided. Some of the manufacturers' capacitor specifications are listed in Table I. designed anc fabricated. The contact pads on these boards were unifornly tinned before mounting the capacitors and the wire attarhments. Three capacitors of each type were subjected to characterization. This procedure was necessary to check for data reproducibility and to determine whether similar or different trends exist in the behavior of the same type of capacitors. Note that all of the capacitor types tested may be interoonnected on printed wiring boards or substrates using thermocompression or thermo-sonic wire-bonding techniques, depending upon the composition of the end-cap metallization. The integrity of these wire bonds at cryogenic temperatures will have to be investigated during future tests.

\begin{tabular}{|c|c|c|c|c|c|c|}
\hline Type/\# & $\begin{array}{c}\text { Capacitance } \\
(\mu \mathrm{F})\end{array}$ & $\begin{array}{c}\text { Capacitance } \\
\text { Tolerance }(\%)\end{array}$ & $\begin{array}{c}\text { Voltage } \\
(\mathrm{VDC})\end{array}$ & $\begin{array}{c}\text { Dissipation } \\
\text { Factor }(\%)\end{array}$ & $\begin{array}{c}\text { Temperature } \\
\left({ }^{\circ} \mathrm{C}\right)\end{array}$ & Manufacturer \\
\hline Solid Tantalum (C1) & 6.8 & 10 & 20 & $<6$ & -55 to +85 & Vishay/Sprague \\
\hline Solid Tantalum (C2) & 4.7 & 10 & 10 & $<6$ & -55 to +85 & Vishay/Sprague \\
\hline Solid Tantalum (C3) & 10.0 & 5 & 15 & $<6$ & -55 to +85 & Vishay/Sprague \\
\hline Ceramic-CRX (C4) & 0.1 & $+80 /-20$ & 25 & $0.06-0.95$ & -196 to +20 & Presidio \\
\hline Ceramic-CRX (C5) & 1.0 & $+80 /-20$ & 12 & $0.06-0.95$ & -196 to +20 & Presidio \\
\hline
\end{tabular}

Table I. Capacitor Specifications.

The surface-mount capacitors were characterized as a function of temperature from $20^{\circ} \mathrm{C}$ to $-190^{\circ} \mathrm{C}$ in terms of their dielectric properties. These properties, which included the capacitance and dissipation factor (DF), were obtained in the frequency range of $50 \mathrm{~Hz}$ to $100 \mathrm{kHz}$ using a GenRad Model 1689 Precision RLC Digibridge. The test frequencies are listed in Table II.

\begin{tabular}{|c|c|c|c|c|}
\hline $50 \mathrm{~Hz}$ & $400 \mathrm{~Hz}$ & $5 \mathrm{kHz}$ & $20 \mathrm{kHz}$ & $70 \mathrm{kHz}$ \\
\hline $100 \mathrm{~Hz}$ & $500 \mathrm{~Hz}$ & $10 \mathrm{kHz}$ & $30 \mathrm{kHz}$ & $100 \mathrm{kHz}$ \\
\hline $200 \mathrm{~Hz}$ & $1 \mathrm{kHz}$ & $15 \mathrm{kHz}$ & $50 \mathrm{kHz}$ & \\
\hline
\end{tabular}

Table II. List of Test Frequencies.

The tests were performed as a function of temperature using a Sun Systems Model ECl2 environmental chamber utilizing liquid nitrogen as the coolant. A temperature rate of change of $10^{\circ} \mathrm{C} / \mathrm{min}$ was used throughout this work. The capacitors were tested at the following temperatures: $20 ; 0 ;-25 ;-50 ;-75 ;-100 ;-125$; $-150 ;-160 ;-170 ;-180$; and $-190^{\circ} \mathrm{C}$. At every test temperature, the components were allowed to soak at that temperature for a period of 30 minutes before any measurements were made. After the last measurement was taken at $-190^{\circ} \mathrm{C}$, the capacitors were allowed to stabilize to room temperature and then the measurements were repeated at room temperature to determine the effect of thermal cycling on the devices.

The capacitors were handled very carefully throughout the tests. Due to the size of the these surface-mount devices, circuit boards with different spacings were

\section{Results}

Three capacitors of each type (Cl-C5) were subjected to characterization. All capacitors of the same type displayed similar behavior with temperature as well as with test frequency and showed good reproducibility. Therefore, the data pnsented and discussed in this paper was obtained for one capacitor of each type. This data was representativis of all the three units tested of the same type.

The capacitance and dissipation factor of the solid tantalum and ceramic capacitors as a function of temperature at four different frequencies are shown in Figures 1 ard 2, respectively. All samples of the same capacitor type display very similar behavior with temperature. The solid tantalum capacitors exhibit a decrease in their capacitance and an increase in their dissipation fictor as the temperature is decreased. These changes, however, tend to be more profound at temperatures below $-100^{\circ} \mathrm{C}$ and at high frequencies. Unlike their solid tantalum counterparts, the ceramic capacitors exhibit an increase in their capacitance with decreasing temperature. In fact, while the initial capacitance neasurements of the ceramic capacitors at room temperature had amounted to about two-tenths of their reported nominal values, the capacitance increases significantly as the temperature is lowered At $-190^{\circ} \mathrm{C}$, the capacitance of these capacitors tends to approach their reported norrinal values. This is due to the fact that these custom-designed capacitors are fabricated utilizing new ceramic fonnulations that attain optimal capacitance 

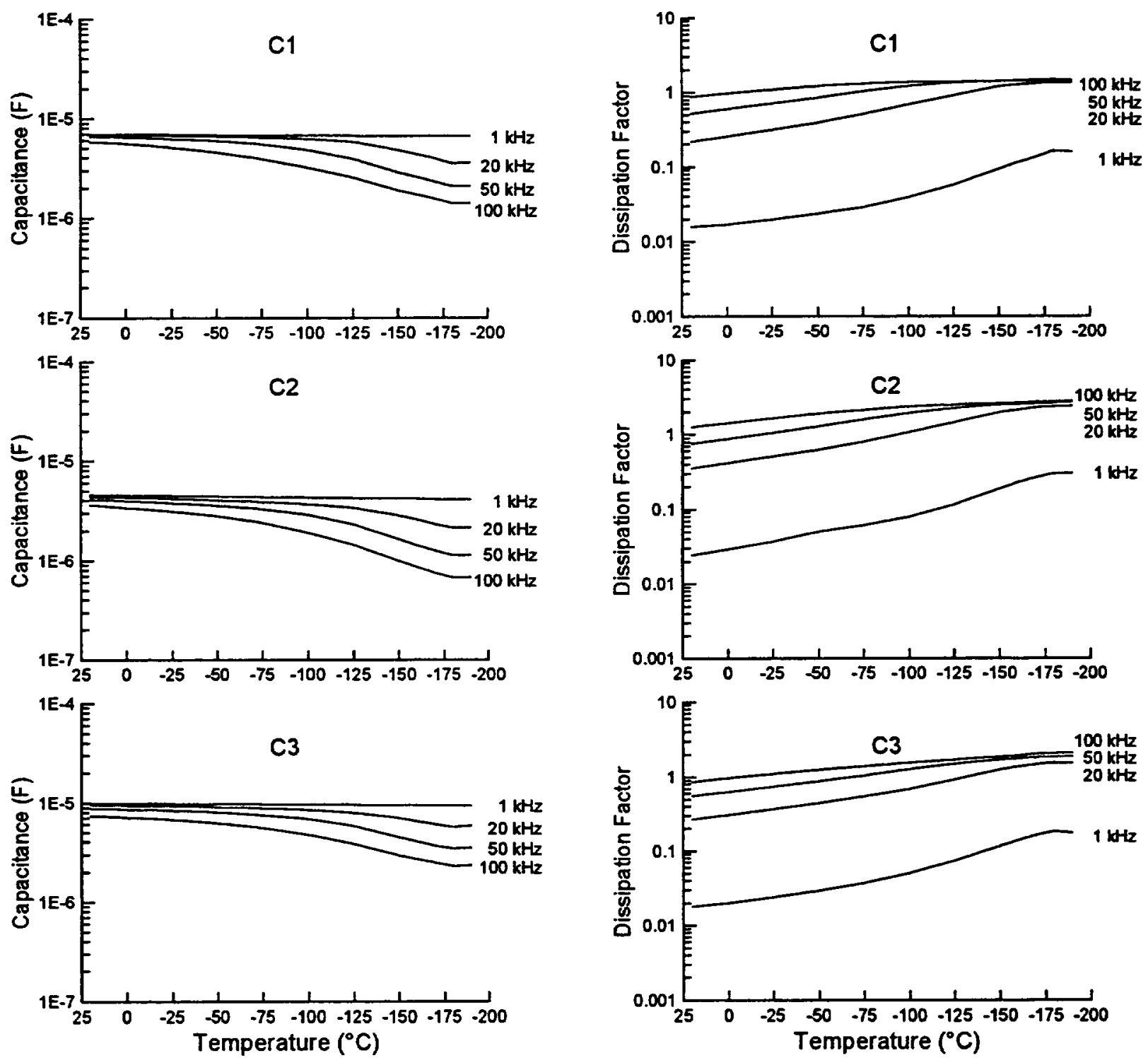

Figure 1. Capacitance and dissipation factor of solid tantalum capacitor $(\mathrm{Cl}, \mathrm{C2}, \mathrm{C} 3)$ as a function of temperature.

values at temperatures around $-200{ }^{\circ} \mathrm{C}$. The dissipation factor of these devices display modest increase only at test temperature below $-125^{\circ} \mathrm{C}$.

The effect of frequency on the dielectric properties of the solid tantalum and ceramic capacitors is depicted in Figure 3. The capacitance as well as the dissipation factor of these capacitors are shown as a function of frequency at five different test temperatures. It is clearly evident that while the capacitance of the ceramic capacitors, at any given temperature, remains very stable with frequency, this property of the solid tantalum capacitors tends to mimic this behavior until a test frequency of $10 \mathrm{kHz}$ is reached. Beyond this frequency, the capacitance exhibits a decrease in its value which becomes appreciable at the very low temperatures. While the effect of frequency on the dissipation factor of the solid tantalum capacitors is well defined, the ceramic capacitors display inconsistent behavior. For example, the dissipation factor of the solid tantalum capacitors, at any given temperature, increases continuously as the frequency is increased. The dissipation factor of the ceramic capacitors, however, exhibits a slight decrease, increase, and sometimes showing a peak characteristic, which indicates strong dependency on the test temperature. Although these trends are inconsistent and occur with varying degrees, the changes in the actual values of the dissipation factor of the ceramic capacitors are not as significant as they appear to be. There were no measured dissipation factor values above 0.01 at $-190^{\circ} \mathrm{C}$ and with $100 \mathrm{kHz}$ excitation for any ceramic multi-layer chip capacitor under test. In fact, these capacitors, which outperform the investigated 

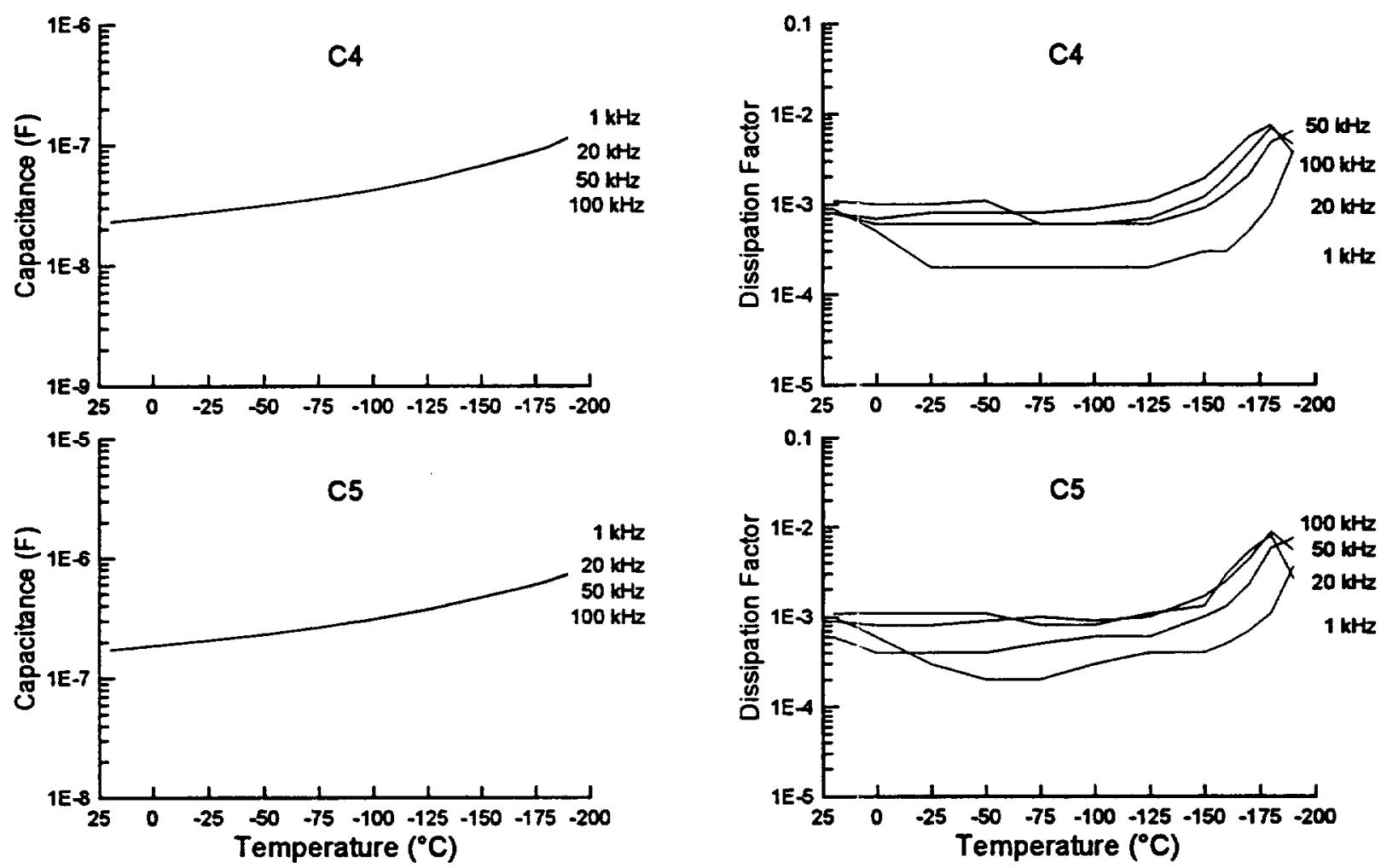

Figure 2. Capacitance and dissipation factor of ceramic capacitor $(\mathrm{C} 4, \mathrm{C} 5)$ as a function of temperature.
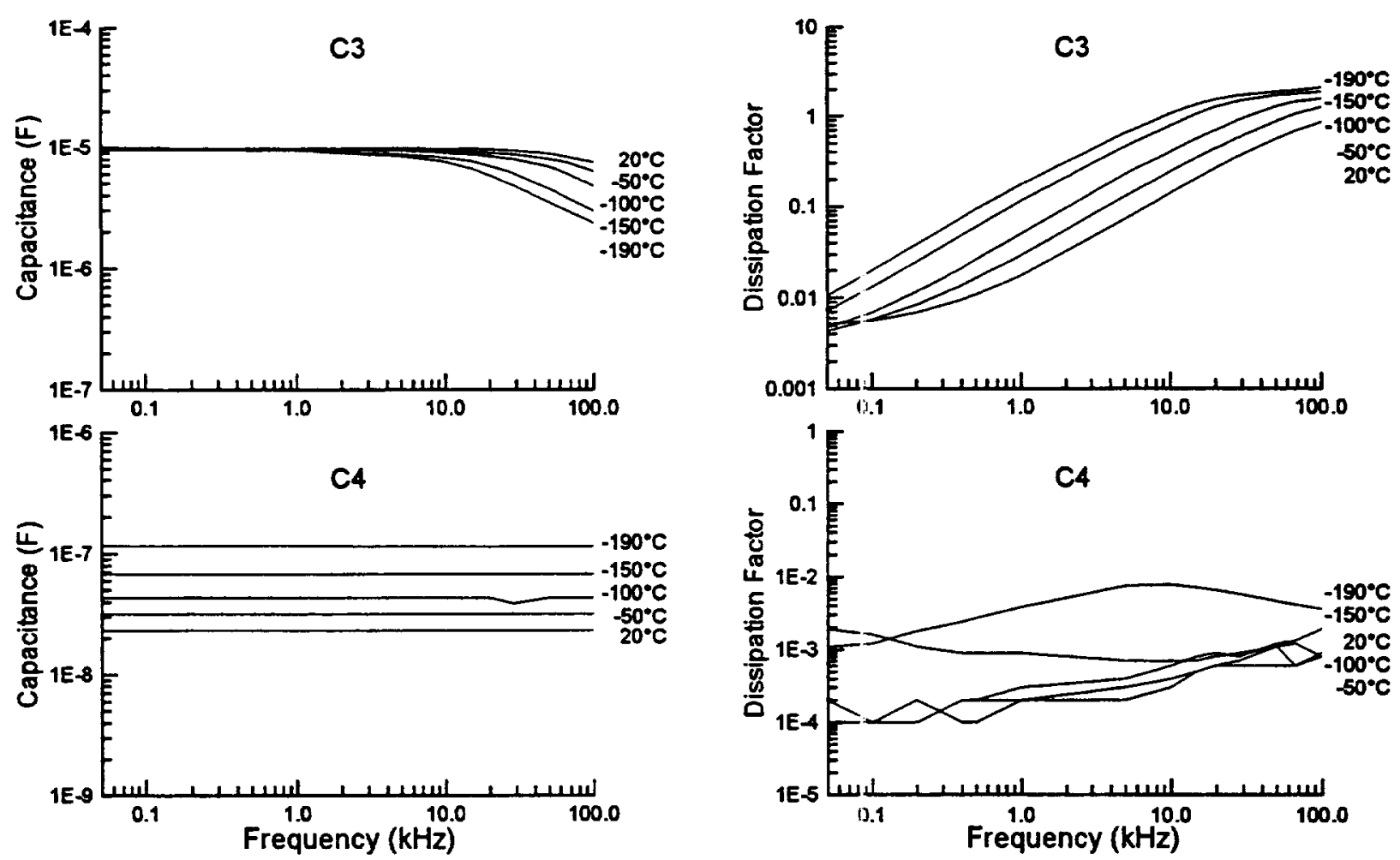

Figure 3. Capacitance \& dissipation factor of solid tantalum (C3) \& ceramic (C4) capacitors vs. frequency. 


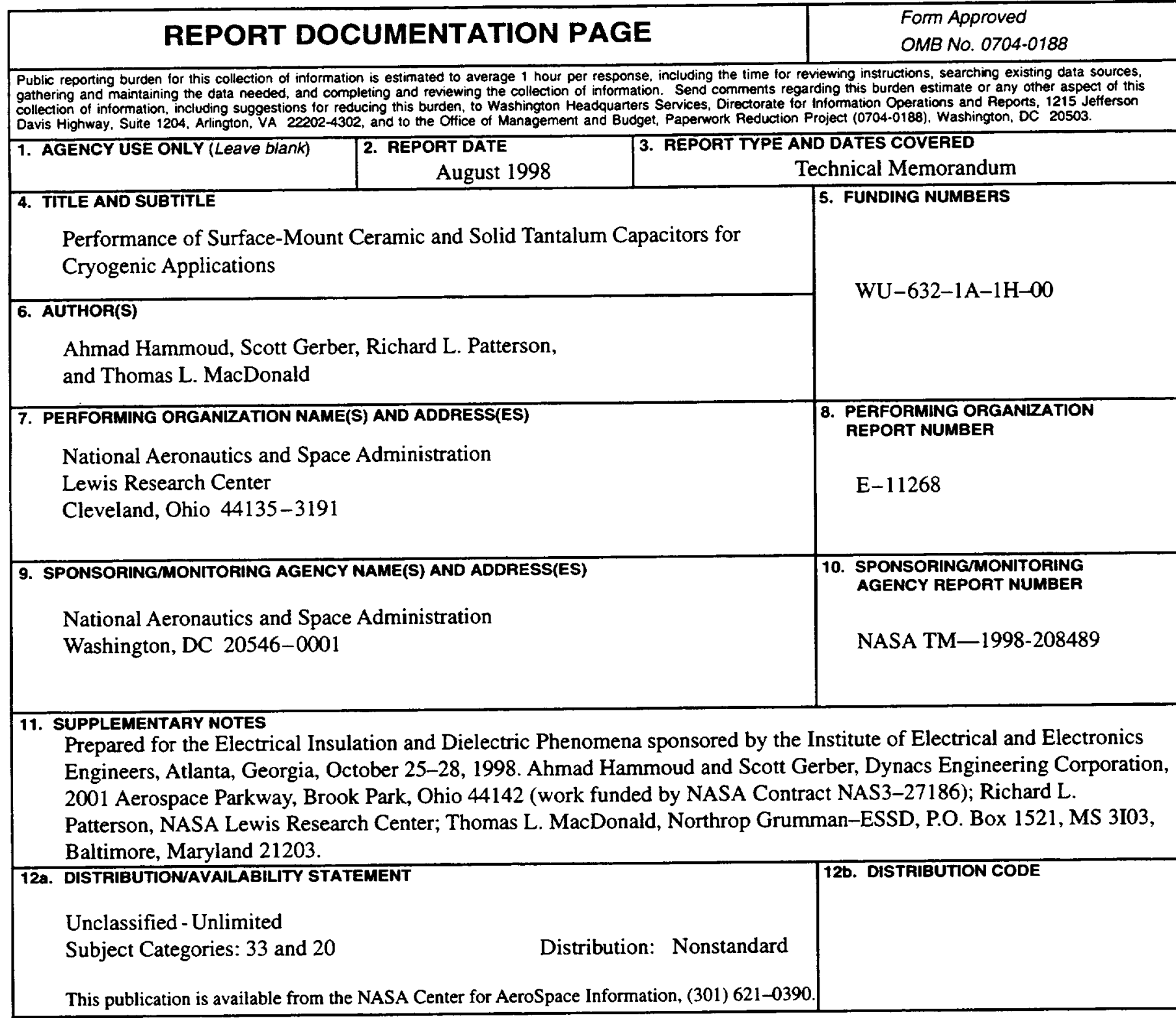

13. ABSTAACT (Max/mum 200 words)

Low temperature electronics are of great interest for space exploration programs. These include missions to the outer planets, earth-orbiting and deep-space probes, remote-sensing and communication satellites. Terrestrial applications would also benefit from the availability of low temperature electronics. Power components capable of low temperature operation would, thus, enhance the technologies needed for the development of advanced power systems suitable for use in harsh environments. In this work, ceramic and solid tantalum capacitors were evaluated in terms of their dielectric properties as a function of temperature and at various frequencies. The surface-mount devices were characterized in terms of their capacitance stability and dissipation factor in the frequency range of $50 \mathrm{~Hz}$ to $100 \mathrm{kHz}$ at temperatures ranging from room temperature $\left(20^{\circ} \mathrm{C}\right)$ to about liquid nitrogen temperature $\left(-190^{\circ} \mathrm{C}\right)$. The results are discussed and conclusions made concerning the suitability of the capacitors investigated for low temperature applications.

\begin{tabular}{|c|c|c|c|}
\hline \multirow{2}{*}{\multicolumn{3}{|c|}{$\begin{array}{l}\text { 14. SUBJECT TERMS } \\
\text { Capacitors; Cryogenic temperature }\end{array}$}} & \multirow{2}{*}{$\begin{array}{l}\text { 15. NUMBER OF PAGES } \\
11 \\
\text { 16. PRICE CODE } \\
\text { AO } 3 \\
\text { 20. LIMITATION OF ABSTRACT }\end{array}$} \\
\hline & & & \\
\hline $\begin{array}{l}\text { 17. SECURITY CLASSIFICATION } \\
\text { OF REPORT }\end{array}$ & $\begin{array}{l}\text { 18. SECURITY CLASSIFICATION } \\
\text { OF THIS PAGE }\end{array}$ & $\begin{array}{l}\text { 19. SECURITY CLASSIFICATION } \\
\text { OF ABSTRACT }\end{array}$ & \\
\hline Unclassified & Unclassified & Unclassified & \\
\hline \multicolumn{3}{|l|}{ NSN 7540-01-280-5500 } & $\begin{array}{l}\text { idard Form } 298 \text { (Rev. 2-89) } \\
\text { cribed by ANSI Sid. Z39-18 } \\
102\end{array}$ \\
\hline
\end{tabular}


solid tantalum ones, possess low dissipation factor values that are comparable to those of dielectric film capacitors.

Measurements of the capacitance and dissipation factor at the test frequency of $100 \mathrm{kHz}$ of the investigated capacitors before, during, and after exposure to low temperature are tabulated in Tables III and IV. As discussed earlier, room temperature measurements were also made after testing the capacitors down to $-190^{\circ} \mathrm{C}$ to determine the effect of thermal cycling on the devices. These post-exposure data are indicated by the last $20^{\circ} \mathrm{C}$ listed in the corresponding tables. Because of the similarity in the behavior of all samples of same capacitor, the data listed are only those pertaining to one sample of each device tested. It is important to note that the dielectric properties of all the capacitors, solid tantalum as well as the ceramic, fully recover to their initial values upon stabilization to the ambient temperature at all test frequencies.

\section{Conclusions}

Three solid tantalum chip and two ceramic multi-layer chip capacitors, manufactured by Vishay/Sprague and Presidio Components respectively, were characterized in terms of their dielectric properties as a function of frequency in the temperature range of $20^{\circ} \mathrm{C}$ to $-190^{\circ} \mathrm{C}$. The temperature-induced changes in the capacitors appear to depend mainly on the dielectric medium being used. For example, while the solid tantalum capacitors experience a slight decrease in capacitance with decrease in temperature, the ceramic capacitors, on the other hand, exhibit a significant increase in this property as the test temperature is decreased. The dissipation factor of both types of capacitors, in general, seem to increase, with varying degrees, as the temperature is lowered. These changes were more noticeable in the solid tantalum capacitors. The frequency was also found to influence the dielectric properties of the solid tantalum capacitors more than those of the ceramic ones. Post-exposure measurements reveal that thermal cycling has no effect on the devices as the investigated properties of all capacitors recover to their original values.

The preliminary results of this work along with further evaluation on other properties such as leakage current, breakdown voltage, and multi-stress testing will greatly contribute to the eventual development of efficient, reliable, and long-life systems qualified for space-borne and other harsh emvironments.

\section{Acknowledgments}

This work was performed under contracts NAS3-27186 (NYMA Inc./FDC Corp.), NAS3-98022 (Northrop Gnumman Corp.) and Reimbursable Space Act Agreement SAA3-116 (GLITEC) with the NASA Lewis Research Center.

\begin{tabular}{|c|c|c|c|c|c|}
\hline $\mathrm{T}\left({ }^{\circ} \mathrm{C}\right)$ & $\mathrm{C} 1$ & $\mathrm{C} 2$ & $\mathrm{C} 3$ & $\mathrm{C} 4$ & $\mathrm{C} 5$ \\
\hline 20 & 5.77 & 3.76 & 7.70 & 0.023 & 0.172 \\
0 & 5.44 & 3.55 & 7.47 & 0.025 & 0.187 \\
-25 & 5.20 & 3.24 & 7.02 & 0.027 & 0.207 \\
-50 & 3.76 & 2.85 & 6.34 & 0.031 & 0.231 \\
-75 & 4.14 & 2.42 & 5.56 & 0.036 & 0.264 \\
-100 & 2.56 & 1.89 & 4.67 & 0.042 & 0.309 \\
-125 & 2.76 & 1.44 & 3.68 & 0.052 & 0.374 \\
-150 & 2.06 & 0.99 & 2.84 & 0.067 & 0.470 \\
-160 & 1.87 & 0.85 & 2.60 & 0.075 & 0.518 \\
-170 & 1.73 & 0.75 & 2.35 & 0.084 & 0.570 \\
-180 & 1.54 & 0.65 & 2.19 & 0.095 & 0.635 \\
-190 & 1.57 & 0.67 & 2.24 & 0.113 & 0.726 \\
20 & 5.82 & 3.71 & 7.94 & 0.022 & 0.170 \\
\hline
\end{tabular}

Table III. Capacitance $(\mu \mathrm{F})$ versus Temp. at $100 \mathrm{kHz}$.

\begin{tabular}{|c|c|c|c|c|c|}
\hline $\mathrm{T}\left(^{\circ} \mathrm{C}\right)$ & $\mathrm{C} 1$ & $\mathrm{C} 2$ & $\mathrm{C} 3$ & $\mathrm{C} 4$ & $\mathrm{C} 5$ \\
\hline 20 & 0.7222 & 1.2430 & 0.8959 & 0.0008 & 0.0011 \\
0 & 0.8073 & 1.4350 & 1.0260 & 0.0007 & 0.0011 \\
-25 & 0.9370 & 1.6520 & 1.1710 & 0.0008 & 0.0011 \\
-50 & $\mathrm{C} .8684$ & 1.8680 & 1.3000 & 0.0008 & 0.0011 \\
-75 & 1.1720 & 2.0940 & 1.4410 & 0.0008 & 0.0008 \\
-100 & 0.8532 & 2.2470 & 1.5690 & 0.0009 & 0.0008 \\
-125 & 1.3000 & 2.4200 & 1.6380 & 0.0011 & 0.0011 \\
-150 & 1.3250 & 2.5730 & 1.8080 & 0.0019 & 0.0013 \\
-160 & 1.3670 & 2.6390 & 1.9010 & 0.0032 & 0.0030 \\
-170 & 1.3830 & 2.6700 & 1.9680 & 0.0056 & 0.0054 \\
-180 & 1.4070 & 2.7210 & 2.0400 & 0.0076 & 0.0081 \\
-190 & 1.3730 & 2.7710 & 2.0240 & 0.0036 & 0.0026 \\
20 & 0.7285 & 1.2190 & 0.9266 & 0.0008 & 0.0011 \\
\hline
\end{tabular}

Table IV. Dissipation Factor versus Temp. at $100 \mathrm{kHz}$.

\section{References}

[1] B. Ray and RL. Patterson, "Wide Temperature Operation of a PWM DC-DC Converter," IEEE Industry Applications Society Conference, Orlando, FL, Oct. 8-12, 1995.

[2] RL. Fatterson, A Hammoud, and S.S. Gerber, "Evaluation of Capacitors at Cryogenic Temperatures for Space Applications," IEEE International Symposium on Electrical Insulation, Washington, DC, June 7-10, 1998.

[3] RK Jirschman, "Low Temperature Electronics Device Operation," The Electro-Chemical Society, pv 91-. 4, 1991.

[4] RL. Patterson, J.E. Dickman, A. Hammoud, and S. Gerber "Low Temperature Power Electronics Progra:n,"NASA EEE Links, Electronic Packaging and Space Parts News, Vol.4, No. 1, January 1998.

[5] J. Schuck, "Design Engineering" Areospace America, Vol. No. 12, December, 1997. 